\title{
Taxa de probabilidade como guia de interpretação do FAN-HEp-2 na pesquisa de autoanticorpos no lúpus eritematoso sistêmico
}

\author{
Likelihood ratio used to interpretation of autoantibody screening test (FAN-HEp-2) in systemic lupus \\ eritematosus
}

Sandra Trevisan Beck'; João Carlos Nunes Silva²; Sandra Schimit'; Juliana Fleck4; Rosane Souza dos Santos ${ }^{4}$

\begin{abstract}
unitermos
Autoanticorpos

Likelihood ratio

Lúpus eritematoso sistêmico

\section{resumo}

Introdução: A magnitude de variação da probabilidade pré-teste de uma doença para uma nova probabilidade pós-teste pode ser determinada pelo cálculo da razão de verossimilhança ou likelihood ratio (LR) do teste, refletindo o valor clínico do resultado obtido no procedimento. Objetivo: Verificar o impacto clínico da pesquisa de autoanticorpos para o diagnóstico do lúpus eritematoso sistêmico (LES) e outras doenças autoimunes por meio das medidas de LR quando utilizadas células HEp-2 para triagem ou pesquisa do anticorpo específico anti-DNA de dupla hélice (anti-dsDNA), mostrando a importância de parâmetros como sensibilidade e especificidade dos testes. Material e métodos: Foram pesquisados autoanticorpos por imunofluorescência indireta (IFI), utilizando-se células HEp-2 e anti-DNA em Crithidia luciliae em amostras de soro de 47 indivíduos com diagnóstico de LES, 27 portadores de outra doença autoimune e 71 apresentando outra patologia. Resultados: A presença de reatividade igual ou superior a 1/160 em células HEp-2 apresenta LR positiva com impacto significativo na probabilidade pós-teste de doença presente, mesmo na ausência de pesquisa complementar. Em soros com reatividade inferior a 1/160, a pesquisa de anti-dsDNA tem grande relevância na determinação do diagnóstico de LES, apresentando grande impacto na probabilidade pós-teste. Discussão: Considerando a sensibilidade e a especificidade do teste de FAN para resultados distribuídos em diferentes intervalos, confirma-se que os resultados com baixo título não modificam significativamente a probabilidade pós-teste da ocorrência da doença. Testes complementares com alta especificidade têm grande valor clínico. O conhecimento de parâmetros como sensibilidade, especificidade e LR dos testes diagnósticos é crucial para uma avaliação clínica eficiente.
\end{abstract}

abstract

Background: The magnitude of variation in pre-test probability of a certain disease to a new post-test probability may be determined through likelihood ratio $(L R)$, which reflects the clinical value of the result obtained in the procedure. Objectives: To verify the clinical impact of autoantibody screening on the diagnosis of Systemic Lupus Erythematosus (SLE) and other autoimmune diseases through LR measurement when HEp-2 cells are used for screening or investigation into anti-Ds-DNA antibody, showing the importance of parameters such as sensitivity and specificity. Material and method: Autoantibodies were studied by indirect immunofluorescence using HEp-2 cells and Crithidia luciliae anti-DNA test in serum samples collected from 47 individuals diagnosed with SLE, 27 with other autoimmune diseases and 71 with other pathologies. Results: The presence of reactivity $\geq 1 / 160$ in HEp-2 cells showed positive $L R$ with significant impact on post-test probability even in the absence of complementary investigation. In serum samples with reactivity $<1 / 160$, anti-dsDNA screening has great relevance to the diagnosis of SLE with a great impact on post-test probability. Discussion: As to sensibility and specificity of FAN test for results grouped into different intervals, it was confirmed that results with low titer do not change post test probability of disease occurrence. Complementary tests with high specificity have major clinical value. Both the investigation of parameters such as sensibility /specificity and likelihood ratio of diagnostic tests have crucial importance in efficient clinical evaluation.

1. Professora doutora da disciplina de Imunologia Clínica do Curso de Farmácia da Universidade Federal de Santa Maria (UFSM).

2. Professor do Departamento de Clínica Médica do Curso de Medicina da UFSM.

3. Acadêmica do curso de Farmácia da UFSM.

4. Farmacêutica bioquímica do setor de Imunologia do Laboratório Central do Hospital Universitário da UFSM. 


\section{Introdução}

O lúpus eritematoso sistêmico (LES) é uma doença autoimune na qual frequentemente são encontrados autoanticorpos reativos contra antígenos nucleares. Muitos destes autoanticorpos não são específicos para LES e podem ser produzidos por ativação policlonal de linfócitos $B^{(2)}$.

Para o diagnóstico de LES costuma-se utilizar a orientação do Colégio Americano de Reumatologia $(A C R)^{(12)}$. São avaliados 11 critérios estabelecidos, em que a presença de pelo menos quatro deles define a patologia. Estando presente ou havendo suspeita de dois dos 11 critérios, já é recomendada a solicitação da pesquisa de anticorpos antinucleares (AAN).

A pesquisa destes autoanticorpos por imunofluorescência indireta (IFI), utilizando como substrato células de epitelioma de laringe humana (HEp-2), é particularmente importante. Este teste não é específico para o diagnóstico de LES, uma vez que apenas sugere a presença de autoanticorpos. Entretanto, direciona o raciocínio clínico e a investigação laboratorial para a pesquisa de anticorpos específicos, como, por exemplo, anti-dsDNA, anti-SSA-Ro e anti-Sm, que poderão caracterizar melhor o quadro laboratorial|(2).

Na maioria das vezes, é o resultado obtido por meio de exames diagnósticos que influenciará a decisão do clínico, embora um determinado teste diagnóstico seja apenas uma das maneiras de aumentar ou diminuir a probabilidade da hipótese diagnóstica de o individuo apresentar ou não a doença.

Na clínica, vários fatores são analisados conjuntamente, uma vez que diferentes doentes apresentam distintos fatores de risco, pertencem a diferentes faixas etárias e apresentam ou não doença associada, o que faz com que a probabilidade de doença varie de um indivíduo para outro. Da mesma forma, existem variações de sensibilidade e especificidade dos métodos empregados nas análises laboratoriais realizadas. Portanto, uma nova informação laboratorial deverá ser avaliada quanto a acurácia, relevância e aplicabilidade na situação em questão. Um teste diagnóstico será útil apenas se os resultados obtidos modificarem a probabilidade da ocorrência ou não da doença(22).

A maneira mais usual de um clínico determinar a probabilidade pré-teste da doença é em termos percentuais. Para isso são levados em conta sinais e evidências clínicas apresentados pelo paciente após anamnese, descrição da doença existente e sua prevalência na literatura e na ex- periência pessoal ${ }^{(8)}$. Após esta análise, o resultado do teste ajudará a transformar a probabilidade pré-teste da doença em uma nova probabilidade pós-teste. A magnitude e o sentido de variação desta mudança de probabilidade podem ser determinados pelo cálculo da razão de verossimilhança (taxa de probabilidade) ou likelihood ratio (LR) do teste. Este parâmetro, apesar de ser pouco conhecido, vem sendo citado e aplicado na literatura científica nos últimos tempos, substituindo a utilização de valores preditivos positivos (VPP) e negativos (VPN) na avaliação do valor clínico do resultado de um teste. Tal mudança é vantajosa, pois esses valores dependem muito da prevalência da patologia na população em estudo. Já o cálculo da LR não sofre esta influência, já que é realizado por meio dos valores de sensibilidade e especificidade apresentados por um determinado teste, estando diretamente ligado à acurácia com a qual o teste identifica a doença em questão ${ }^{(11)}$. Por esta razão, determina com mais precisão o poder que o resultado de um teste diagnóstico terá na mudança de opinião do clínico.

O valor de LR pode ser calculado tanto para resultados negativos (probabilidade de excluir a doença) como para positivos (probabilidade de confirmar a doença) do teste.

Quanto mais o valor de LR se afasta da unidade (em ambos os sentidos), mais poderoso é o teste em termos discriminativos/diagnósticos ${ }^{(20)}$ (Tabela 1).

Efeito do valor de LR na probabilidade Tabela 1 pós-teste de doença

\begin{tabular}{|c|c|c|}
\hline $\begin{array}{l}\text { LR para } \\
\text { resultados } \\
\text { positivos }\end{array}$ & $\begin{array}{l}\text { LR para } \\
\text { resultados } \\
\text { negativos }\end{array}$ & $\begin{array}{c}\text { Efeito na } \\
\text { probabilidade pós- } \\
\text { teste da doença }\end{array}$ \\
\hline $\begin{array}{l}\text { Maior } \\
\text { que10 }\end{array}$ & Menor que 0,1 & Grande \\
\hline $\begin{array}{l}\text { Entre } 5 \text { e } \\
10\end{array}$ & Entre 0,1 e 0,2 & Moderado \\
\hline $\begin{array}{l}\text { Entre } 2 \text { e } 5 \\
\text { Igual a } 1\end{array}$ & $\begin{array}{l}\text { Entre } 0,2 \text { e } 0,5 \\
\text { Igual a } 1\end{array}$ & $\begin{array}{l}\text { Mínimo } \\
\text { Nenhum }\end{array}$ \\
\hline
\end{tabular}

Na reumatologia, diferentes testes laboratoriais são utilizados como auxílio ao diagnóstico clínico. Em vista disso, um parâmetro que mensure a força discriminativa do resultado emitido pelo laboratório é de grande valia.

A triagem por meio de células HEp-2 apresenta, para pesquisa de anticorpos antinucleares, alta sensibilidade (93\%-100\%), mas baixa especificidade (57\%), uma vez que estes autoanticorpos são encontrados em pacientes com outras doenças e mesmo em indivíduos hígidos ${ }^{(1)}$. 
A valorização dos títulos encontrados nas pesquisas de anticorpos antinucleares tem mostrado algum significado clínico na avaliação diagnóstica quando considerados relevantes títulos iguais ou superiores a 1/160, aumentando a especificidade do teste no momento de sua interpretação, porém com perda de sensibilidade ${ }^{(24)}$.

Outros aspectos importantes são as relevâncias clínicas de cada padrão de fluorescência apresentado pelas células HEp-2. Existem associações bem estabelecidas na literatura que, embora relativas, têm grande valor no momento da solicitação, pelo clínico, de testes imunológicos específicos para a identificação dos autoanticorpos sugeridos no teste de fator antinuclear (FAN).

A determinação de anti-dsDNA é particularmente importante por ser um dos marcadores úteis para confirmar o diagnóstico de pacientes com FAN reagente que não preenchem os critérios do ACR para $\mathrm{LES}^{(6)}$ e por estar correlacionado com alguns aspectos e prognósticos importantes da doença, como lúpus ativo ou nefrite. Estes anticorpos são encontrados no LES em $30 \%$ a $88 \%$ dos pacientes ${ }^{(15)}$, além de apresentarem grande especificidade para esta patologia. Segundo o II Consenso Brasileiro de Fator Antinuclear em Células HEp- $2^{(5)}$, a presença do anticorpo anti-dsDNA estaria relacionada apenas com o padrão de fluorescência nuclear homogêneo, não sendo necessária a solicitação de sua pesquisa quando outros padrões de fluorescência forem relatados ${ }^{(5)}$.

Tendo em vista os diferentes fatores que precisam ser considerados na interpretação de um teste laboratorial, o presente trabalho procurou demonstrar o impacto clínico da pesquisa de autoanticorpos para o diagnóstico de LES e outras doenças autoimunes, quando utilizado o método de IFI em células HEp-2 e/ou pesquisa de anticorpos antidsDNA, pelo cálculo e pela interpretação da LR dos testes, mostrando o valor da aplicação deste parâmetro no momento da valorização dos resultados emitidos.

\section{Material e métodos}

\section{Casuística}

Foram analisadas amostras de soro encaminhadas ao laboratório de análises clínicas de 145 pacientes para determinar a presença de autoanticorpos. Pela análise de prontuários foram identificados 47 indivíduos com diagnóstico de LES, 27 portadores de outra doença autoimune (doença de Graves, tireoidite de Hashimoto, artrite reumatoide, dia- betes mellitus tipo 1 [DM1, síndrome de Sjögren, hepatite autoimune) e 71 pacientes sem doenças autoimunes (asma, pneumonia, hepatite $B$, hepatite $C$, HIV, linfoma, tuberculose, artralgia, psoríase, depressão, acidente vascular cerebral [AVC], úlcera péptica, insuficiência renal crônica).

Todos os exames foram realizados a partir de requisições encaminhadas pelo clínico responsável. A Comissão de Pesquisa e Ética em Saúde do Grupo de Pesquisa do Hospital Universitário de Santa Maria e do Centro de Ciências da Saúde da Universidade Federal de Santa Maria (UFSM) avaliou e aprovou os itens estudados (Protocolo no 118/2004).

\section{Pesquisa de autoanticorpos}

A determinação da presença de autoanticorpos foi realizada por IFI, utilizando células HEp-2, (Hemagen - Virgo ${ }^{\circledR}$ Products Division, Columbia, Maryland 21045, USA).

A determinação da presença de anti-dsDNA foi realizada por IFI, tendo como substrato Crithidia luciliae (IFICL) (Immunoconcepts ${ }^{\circledast}$ Sacramento, California, USA).

Os soros foram testados, segundo recomendações do fabricante, em diluições a partir de $1 / 40$ para pesquisa de anticorpos utilizando células HEp-2 e 1/10 para pesquisa de anticorpos anti-dsDNA. Para deteç̧ão dos autoanticorpos fixados foi utilizado conjugado fluorescente anti-imunoglobulina da classe $G$ (anti-lgG) humana (Immunoconcepts ${ }^{\circledR}$ Sacramento, California, USA). As incubações foram realizadas em temperatura ambiente. Ao final, as lâminas recobertas com glicerina alcalina e lamínula foram observadas em microscópio de imunofluorescência (400x).

Para determinar o impacto clínico da pesquisa de anticorpos anti-dsDNA pelos métodos de IFICL e ensaio imunossorvente ligado à enzima (ELISA), foram utilizados os parâmetros de sensibilidade e especificidade encontrados na literatura ${ }^{(10)}$ (anti-dsDNA obtidos por IFICL: $41 \%$ de sensibilidade e $99 \%$ de especificidade; anti-dsDNA utilizando o método de ELISA - Varelisa, Pharmacia ${ }^{\circledR}$ : sensibilidade de $79 \%$ e especificidade de $73 \%$ ) em estudo comparando pacientes com LES e indivíduos com outras patologias.

\section{Determinação de ponto de corte}

Para determinar a partir de que título um teste de FAN mostrou valor clínico para diagnóstico de LES ou doença autoimune, foi construída uma receive operator caracteristic curve (ROC). Esta curva é definida como a descrição gráfica do desempenho de um teste representado pela relação entre a taxa de verdadeiro-positivos (sensibilidade) e taxa 
de falso-positivos (1 - especificidade) ${ }^{(19)}$. Esta curva é construída a partir dos diferentes índices de sensibilidade e especificidade e obtida com diferentes valores de ponto de corte. Para cada ponto de decisão são colocados os índices de verdadeiro-positivos (sensibilidade), que estarão representados no eixo das ordenadas, e os índices de falsopositivos (1 - especificidade), que estarão representados no eixo das abscissas, mostrando as variações ponto a ponto para cada ponto de corte possível(9).

\section{Cálculo da $\mathbf{L R}^{(11)}$}

Para testes com resultado positivo:

$$
\operatorname{LR}(+)=\frac{\text { sensibilidade }}{1-\text { especificidade }}
$$

Para testes com resultados negativos:

$$
\operatorname{LR}(-)=1-\frac{\text { sensibilidade }}{\text { especificidade }}
$$

A Tabela 2 mostra como calcular a LR quando mais de dois resultados são possíveis.

\section{Cálculo do LR quando mais de dois}

Tabela 2 resultados são possíveis

\begin{tabular}{lccc}
\hline $\begin{array}{l}\text { Resultado } \\
\text { do teste }\end{array}$ & $\begin{array}{c}\text { Doença } \\
\text { presente }\end{array}$ & $\begin{array}{c}\text { Doença } \\
\text { ausente }\end{array}$ & Total \\
A & a & $b$ & $a+b$ \\
B & $c$ & $d$ & $c+d$ \\
C & $e$ & $f$ & $e+f$ \\
Total & $x$ & $y$ & $z$
\end{tabular}

a, b, c, d, e, f representam o número de pacientes em cada categoria.

$$
\begin{aligned}
& \text { LR para resultado } A=(a / x) /(b / y) \\
& \text { LR para resultado } B=(c / x) /(d / Y) \\
& \text { LR para resultado } C=(e / x) /(f / Y)
\end{aligned}
$$

\section{Probabilidade pós-teste(3)}

Depois do cálculo da LR do teste para diferentes títulos, é possível calcular a alteração da probabilidade pré-teste ocasionada pelo resultado. Para isso a probabilidade préteste (\%) é transformada em razão (chance) pelo seguinte cálculo:
Chance $=$ probabilidade $/(1-$ probabilidade $)$

Chance pré-teste $\times \mathrm{LR}=$ chance pós-teste

Para expressar o valor em percentuais utilizamos:

Probabilidade $=$ chance $/($ chance +1$)$

Ex.: se a probabilidade pré-teste for de 0,8 (80\%), então:

Chance $=0,8 /(1-0,8)=0,8 / 0,2=4 / 1$

Ex.: se chance $=4 / 1$, então:

Probabilidade pós-teste $=(4 / 1) /(4 / 1)+1=4 / 5=0,8$ $(80 \%)$

\section{Resultados}

Considerando os resultados de FAN obtidos após a análise dos soros dos pacientes com LES e daqueles sem doenças autoimunes, foram avaliadas diferentes diluições para determinação do ponto de corte. Pode-se observar que a diluição em que encontramos melhor sensibilidade com menor número de resultados falso-positivos foi a de 1/160: sensibilidade de $52 \%$ e especificidade de $91,5 \%$. Se forem agrupados os pacientes com LES e outras doenças autoimunes $(n=74)$, verifica-se a manutenção do ponto de corte na diluição 1/160, porém a sensibilidade do teste diminui, passando a ser de $46,6 \%$ (Figura).

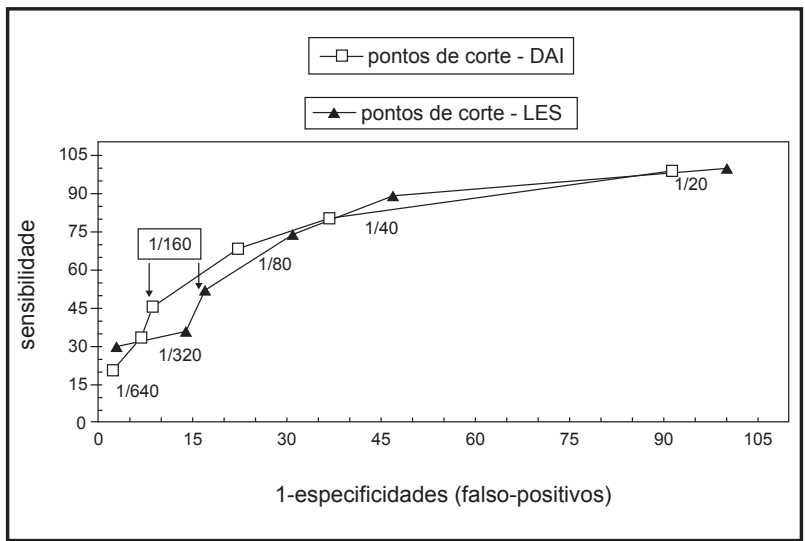

Figura - Curva ROC para determinação do ponto de corte para diagnóstico de LES e doença autoimune

- T: Títulos (diluições) utilizados como pontos de corte.

ROC: receive operator caracteristic curve; LES: lúpus eritematoso sistêmico; DAl: doença autoimune. 


\section{Impacto do resultado de FAN na probabilidade pré-teste}

O cálculo de LR para os diferentes resultados de FAN foi realizado a partir da distribuição dos pacientes segundo o título de FAN encontrado na amostra analisada. Foram analisados pacientes com LES versus os sem doenças autoimunes (Tabela 3); com LES versus aqueles com outras doenças autoimunes (Tabela 4); e os com doença autoimune (incluindo LES) versus pacientes sem doenças autoimunes (Tabela 5). Partiu-se da premissa de que a probabilidade pré-teste da presença da doença era de $50 \%$, uma vez que é nesta situação que um teste diagnóstico torna-se extremamente necessário.

\section{Pesquisa do anticorpo anti-dsDNA}

Não foi possível obter a pesquisa de anti-dsDNA de todos os indivíduos envolvidos no presente estudo. Entre os 47 pacientes com diagnóstico de LES, 38 a realizaram, resultando positivos $42 \%(16 / 38)$, o que confirmou a sensibilidade do teste descrita na literatura. Apenas seis pacientes com outras doenças autoimunes e 10 dos sem doenças autoimunes tiveram realizada a pesquisa deste anticorpo, não permitindo a avaliação da especificidade do teste no presente trabalho. Por esta razão, os LRs positivo e negativo para pesquisa de anticorpos anti-dsDNA foram calculados com base em valores de sensibilidade e especifi-

Tabela 3

Probabilidade pós-teste após resultado de FAN para diagnóstico de LES com relação a

\begin{tabular}{lccccc}
\hline \multicolumn{1}{c}{ Título do FAN } & LES $(n)$ & $\begin{array}{c}\text { Patologia } \\
\text { não-autoimune }(n)\end{array}$ & $\begin{array}{c}\text { Pré-teste }(\%) \\
\text { LR* }^{*}\end{array}$ & Pós-teste $(\%)^{*}$ \\
$<1 / 40$ & 5 & 42 & 50 & 0,16 & 13 \\
$1 / 40-1 / 80$ & 18 & 23 & 50 & 1,18 & 54 \\
$1 / 160-1 / 320$ & 10 & 5 & 50 & 2,85 & 74 \\
$\geq 1 / 640$ & 14 & 1 & 50 & 21,4 & 95 \\
Total & 47 & 71 & - & - & -
\end{tabular}

*Cálculo conforme descrito em "Material e métodos".

FAN: fator antinuclear; LES: lúpus eritematoso sistêmico; LR: likelihood ratio.

Probabilidade pós-teste após resultado de FAN para diagnóstico de LES com relação a

Tabela 4 pacientes com outra doença autoimune

\begin{tabular}{lccccc}
\hline Título do FAN & LES $(n)$ & $\begin{array}{c}\text { Outra patologia } \\
\text { autoimune }(n)\end{array}$ & Pré-teste $(\%)$ & LR $^{*}$ & Pós-teste $(\%)^{*}$ \\
$<1 / 40$ & 5 & 9 & 50 & 0,33 & 24 \\
$1 / 40-1 / 80$ & 18 & 7 & 50 & 1,46 & 59 \\
$1 / 160-1 / 320$ & 10 & 9 & 50 & 0,6 & 37 \\
$\geq 1 / 640$ & 14 & 2 & 50 & 4,2 & 81 \\
Total & 47 & 27 & - & - & -
\end{tabular}

*Cálculo conforme descrito em "Material e métodos".

FAN: fator antinuclear; LES: lúpus eritematoso sistêmico; LR: likelihood ratio.

Tabela 5 Probabilidade pós-teste após resultado de FAN para diagnóstico de doença autoimune

\begin{tabular}{lccccc}
\hline Título do FAN & $\begin{array}{c}\text { Patologia } \\
\text { autoimune }(n)\end{array}$ & $\begin{array}{c}\text { Patologia não- } \\
\text { autoimune }(n)\end{array}$ & Pré-teste $(\%)$ & LR $^{*}$ & Pós-teste $(\%)^{*}$ \\
$<1 / 40$ & 14 & 42 & 50 & 1,3 & 56 \\
$1 / 40-1 / 80$ & 25 & 23 & 50 & 1,09 & 52 \\
$1 / 160-1 / 320$ & 19 & 5 & 50 & 35,7 & 97 \\
$\geq 1 / 640$ & 16 & 1 & 50 & 15 & 94 \\
TOTAL & 74 & 71 & - & - & -
\end{tabular}

*Cálculo conforme descrito em "Material e métodos".

FAN: fator antinuclear; LR: likelihood ratio. 
cidade descritos na literatura ${ }^{(10)}$, resultando para o teste de IFICL valores de LR positiva igual a 41 e LR negativa igual a 0,59; e para o teste de ELISA, valores de LR positiva igual a 2,9 e negativo igual a 0,28 .

Desta forma, se considerarmos a probabilidade pré-teste, a probabilidade de diagnóstico de LES pós-teste de FAN, demonstrada na Tabela 6, poderemos observar a mudança de probabilidade do diagnóstico da doença quando associada à pesquisa de anti-dsDNA.
O teste de FAN é considerado de triagem para a pesquisa de autoanticorpos. Porém, a presença de resultados falso-positivos é comum. Aproximadamente $20 \%$ dos indivíduos normais apresentam título de FAN reagente em diluição $1 / 40$ e 5\%, FAN igual ou maior que $1 / 160$. Por este motivo, vários estudos têm sugerido que apenas resultados com títulos iguais ou maiores que 1/160 teriam aplicação clínica, embora necessitem de maiores avaliações ${ }^{(23,24)}$. Esse título foi confirmado no presente estudo pela curva ROC

\begin{tabular}{|c|c|c|c|c|c|}
\hline \multirow{2}{*}{$\begin{array}{l}\text { Tabela } 6 \\
\text { Título do FAN }\end{array}$} & \multicolumn{5}{|c|}{$\begin{array}{l}\text { Probabilidade pós-teste após resultado de FAN acrescido de pesquisa de anticorpos } \\
\text { anti-dsDNA por IFICL e por ELISA para diagnóstico de LES }\end{array}$} \\
\hline & $\begin{array}{l}\text { Pré-teste LES } \\
\qquad(\%)^{* *}\end{array}$ & $\begin{array}{l}\text { Probabilidade de } \\
\text { LES IFICL positivo } \\
\text { (LR = 41) (\%)* }\end{array}$ & $\begin{array}{l}\text { Probabilidade de } \\
\text { LES ELISA positivo } \\
(\text { LR }=2,9)(\%)^{*}\end{array}$ & $\begin{array}{l}\text { Probabilidade de } \\
\text { LES IFICL negativo } \\
(\text { LR }=0,59)(\%)^{*}\end{array}$ & $\begin{array}{l}\text { Probabilidade de } \\
\text { LES ELISA negativo } \\
(\text { LR }=0,28)(\%)^{*}\end{array}$ \\
\hline$<1 / 40$ & 13 & 86 & 30 & 7 & 4 \\
\hline $1 / 40-1 / 80$ & 54 & 98 & 77 & 40 & 23 \\
\hline $1 / 160-1 / 320$ & 74 & 99 & 89 & 62 & 44 \\
\hline$\geq 1 / 640$ & 95 & 99,8 & 98 & 92 & 84 \\
\hline
\end{tabular}

*Cálculo conforme descrito em "Material e métodos", considerando pesquisa anti-dsDNA com sensibilidade de 41\% e especificidade de 99\% (IFICL); sensibilidade de $79 \%$ e especificidade $73 \%$ (ELISA) ${ }^{(10)}$.

**Dados da Tabela 2 .

FAN: fator antinuclear; anti-dsDNA: anti-DNA de dupla hélice; IFICL: imunofluorescência indireta tendo como substrato Crithidia luciliae; ELISA: ensaio imunossorvente ligado à enzima; LES: lúpus eritematoso sistêmico; LR: likelihood ratio.

\section{Discussão}

Testes sorológicos são amplamente aplicados na pesquisa de doenças reumáticas e autoimunes, permitindo uma classificação mais precisa da patologia no momento de definir o diagnóstico do paciente. Por existir uma ampla variedade de testes imunológicos disponíveis no mercado, é preciso que os resultados emitidos pelos laboratórios sejam interpretados com cuidado pelo clínico e que alguns critérios sejam respeitados.

$\mathrm{Na}$ tentativa de definir a melhor maneira de utilizar os testes laboratoriais, o ACR formou um comitê, responsável por desenvolver um guia de normas (CGN) para interpretação dos ensaios imunológicos empregados no diagnóstico das doenças reumáticas, tendo como base a medicina baseada em evidências. Neste contexto, as medidas de LR positiva e LR negativa de cada teste foram amplamente empregadas(4). Entre os testes avaliados encontram-se a pesquisa de autoanticorpos $(\text { FAN })^{(21)}$ e a de anticorpos anti-dsDNA ${ }^{(16)}$, que foram também realizadas no presente estudo.
(Figura). Contudo, a sensibilidade do FAN, que foi de aproximadamente $90 \%$ (42/47), quando considerado qualquer título acima de $1 / 40$ como positivo, passou a ser de $52 \%$ para diagnóstico de LES e $46 \%$ para doenças autoimunes quando o ponto de corte 1/160 foi aplicado (Figura). Assumir como significativo apenas o título de FAN igual ou superior a 1/160 poderia induzir o clínico a desconsiderar os títulos mais baixos encontrados em pacientes com suspeita da doença, descartando um dos 11 critérios para o diagnóstico de LES segundo o $\mathrm{ACR}^{(12)}$. Segundo Tozzoli et al.(.24), títulos iguais ou maiores que $1 / 40$ e menores que $1 / 160$, devem ser considerados positivos com baixo título, e, na ausência de sintomas específicos, o paciente deve ser apenas monitorado clinicamente. Estes títulos, apesar de pouco frequentes em indivíduos com doença autoimune, podem ter valor clínico, uma vez que estão presentes em pacientes com LES, esclerose sistêmica e síndrome de Sjögren ${ }^{(23)}$.

Tendo em vista a importância do título no resultado de FAN, o cálculo da LR para este teste foi realizado considerando-se suas sensibilidade e especificidade para os diferentes intervalos de reatividade $(<1 / 40 ; 1 / 40-1 / 80 ; 1 / 160-1 / 320$; $\geq 1 / 640$ ). 
Quando foi avaliada a magnitude da mudança de probabilidade para a presença de LES com relação a outras patologias não-autoimunes (Tabela 3), a LR positiva encontrada foi de 2,85 , quando o intervalo considerado $(1 / 160-1 / 320)$ partiu do ponto de corte determinado pela curva ROC (1/160). Este valor foi muito próximo à LR positiva de 2,2 descrito pelo guia de normas do ACR, apresentando impacto moderado na mudança de conduta do clínico. Entretanto, se considerados apenas os pacientes com títulos de FAN acima de 1/640, o impacto do resultado na probabilidade de doença pós-teste torna-se importante, pois com uma LR positiva de 21,4, a probabilidade de LES passa a ser $95 \%$, muito superior aos $50 \%$ iniciais. De outra forma, títulos inferiores a 1/40 apresentam moderado impacto na mudança de decisão, podendo ser considerados para a exclusão de LES, alterando a probabilidade de doença de $50 \%$ para $13 \%$ (Tabela 3).

Se o teste de FAN for utilizado na tentativa de discriminar a presença de LES entre outras doenças autoimunes, não apresentará o mesmo desempenho. Isto pode ser verificado na Tabela 4, onde as LR positivas mostram-se baixos ou próximos a 1, com alguma relevância apenas quando encontrados valores de FAN acima de $1 / 640$. Por essas razões, o guia de normas do ACR recomenda que este teste não seja utilizado para descartar a presença de outras doenças reumáticas. Se o FAN resultar positivo, a pesquisa de autoanticorpos específicos deve ser considerada para auxilio ao diagnóstico(21).

Melhores resultados foram observados quando a pesquisa de FAN foi aplicada para a determinação de presença ou não de doença autoimune. Neste caso, o ponto de corte de 1/160 foi extremamente eficiente, pois resultados com títulos abaixo do ponto de corte determinado (Figura) apresentam LR positiva próximos a 1 (sem impacto clínico) e resultados com valores iguais ou acima do ponto de corte mostram grande valor clínico, com LR positiva de 35,7 e 15, conforme a diluição considerada, modificando a probabilidade da doença de $50 \%$ para $97 \%$ e $94 \%$, respectivamente (Tabela 5). Diante de tal resultado, o desempenho do teste em relação à relevância clínica do resultado justifica a perda na sensibilidade imposta pelo ponto de corte mais alto.

Após um resultado positivo de FAN, indiscutivelmente o clínico direcionará sua conduta para a pesquisa de autoanticorpos específicos. Entre os autoanticorpos relacionados com doenças autoimunes, o anti-dsDNA tem grande importância no momento de um diagnóstico de LES. Embora este anticorpo tenha sido reportado em outras patologias ${ }^{(14,18)}$, sua prevalência é muito baixa $(<5 \%$, com raras exceções), e, quando presente, frequentemente apresenta-se com títulos baixos. Este anticorpo não só serve como marcador laboratorial do LES como também está envolvido diretamente em processos patológicos, como a glomerulonefrite lúpica ${ }^{(7,13)}$.

A sensibilidade para a detecção deste anticorpo varia consideravelmente entre os estudos publicados, fazendo consequentemente variar a LR do teste. O melhor método para determinação desse anticorpo é controverso. Os métodos imunoenzimáticos (ELISA) mostram maior sensibilidade, porém detectam anticorpos de baixa afinidade, que têm menor relevância no LES, principalmente na nefrite. A imunofluorescência utilizando como fonte de DNA Chritidia luciliae apresenta melhor especificidade por não detectar este tipo de anticorpo ${ }^{(10,25)}$. Outro problema referente aos testes ELISA diz respeito à padronização dos métodos existentes no mercado. São utilizados substratos diferentes, contaminação com ssDNA que não são específicos do LES e podem ser detectados diferentes isotipos de anticorpos (lgG, IgA, lgM), dificultando a comparação de resultados ${ }^{(2)}$.

Se não considerado o método utilizado para detecção de anti-dsDNA, e analisando-se estudos que usam como controle indivíduos sadios e com outras patologias, a sensibilidade média para o diagnóstico de LES será de $57,3 \%$, com especificidade de $97,4 \%$ e LR negativa igual a 0,49. A LR positiva na maioria das vezes apresentará valores superiores a 10 ${ }^{(16)}$. Os valores de LR para determinação de anticorpos anti-dsDNA empregados no presente trabalho foram utilizados após terem sido determinados a partir de estudo que comparou pacientes com LES e indivíduos sem doença autoimune ${ }^{(10)}$, mesmo critério utilizado para determinar a probabilidade de LES pós-teste de FAN, descrito na Tabela 3.

Segundo as recomendações do guia de normas do $A C R$, a pesquisa de anticorpos anti-dsDNA é muito útil, principalmente onde a probabilidade inicial do diagnóstico de LES está presente ${ }^{(16)}$. Isto pode ser confirmado quando considerado como probabilidade inicial de LES um resultado positivo para a pesquisa de FAN. Independente do título de autoanticorpos encontrado no teste de triagem, a pesquisa de anticorpos anti-dsDNA positiva praticamente confirma o diagnóstico (Tabela 6). O impacto clínico é maior quando esta pesquisa é feita pela técnica de IFICL, e não por ELISA, menos específico. Isto é ainda mais evidente quando analisado o intervalo de reatividade em que são considerados FANs com títulos inferiores a 1/40 (não-reagentes). Nesta situação, a probabilidade 
de LES passa de $13 \%$ a $86 \%$ após a pesquisa positiva de anti-dsDNA por IFICL e para $30 \%$ quando realizada pelo método ELISA. Contudo, anti-dsDNA positivo acompanhado de FAN negativo acontece com uma frequência de $0 \%$ a $0,8 \%(14,17)$. Uma pesquisa de anti-dsDNA positiva não pode, por si só, ser considerada diagnóstico de LES, devendo ser reservada apenas para pacientes com FANHEp-2 reagentes apresentando padrão de fluorescência homogêneo ${ }^{(5,16)}$. Da mesma forma, nem todos os pacientes com LES apresentam pesquisa de anticorpos anti-dsDNA positiva, então uma pesquisa negativa para este anticorpo não exclui o diagnóstico de LES, principalmente quando a reatividade encontrada em células HEp-2 for igual ou superior a 1/160 (Tabela 6 ).

Como visto, a interpretação correta de um resultado laboratorial no contexto clínico deve levar em consideração uma variedade de fatores. O uso da LR para avaliação dos testes imunológicos no campo da reumatologia mostra-se extremamente aplicável, sendo um parâmetro confiável por não sofrer influência da prevalência da doença, podendo vir a ser um dado auxiliar importante no momento do clínico definir um diagnóstico.

\section{Referências}

1. COLGLAZIER, C. L.; SUTEJ, P. G. Laboratory testing in the rheumatic diseases: a practical review. South Med J, v. 98, p. 185-91, 2005.

2. EGNER, W. The use of laboratory tests in the diagnosis of SLE. J Clin Pathol, v. 53, p. 424-32, 2000.

3. GAMBINO, S. R. Odds, probability and likelihood ratios. Lab Report, v. 8, p. 69-71, 1986.

4. GUIDELINES FOR IMMUNOLOGIC LABORATORY TESTING IN THE RHEUMATIC DISEASES. An introduction: American College of Rheumatology ad hoc comité on immunologic testing guidelines. Artritis \& Rheumatism, v. 47, p. 429-33, 2002.

5. GUIMARÃES, F. N. C. et al. II Consenso Brasileiro de Fator Antinuclear em Células HEp-2 - Definições para a padronização da pesquisa de auto-anticorpos contra constituintes do núcleo (FAN HEp-2), nucléolo, citoplasma e aparelho mitótico e suas associações clínicas. Rev Bras Reumatol, v. 43 n. 3 p. 129-40, 2003.

6. HABASH-BSEISO, D. E. et al. Serologic testing in connective tissue diseases. Clinical Medicine Research, v. 3 n. 3 , p. 190-3, 2005.

7. HAHN, B. H. Antibodies to DNA. N Engl J Med, v. 338, p. 1359-68, 1998.

8. HALKIN, A. et al. Likelihood ratios: getting diagnostic testing into perspective. Q J Med, v. 91, p. 247-58, 1998.

9. HANLEY, J. A. Receiver operating characteristic (ROC) methodology: the state of the art. Crit Rev Diagn Imaging, v. 29, p.307-35, 1989.

10. HAUGBRO, K. et al. Anti-dsDNA antibodies and disease classification in antinuclear antibody positive patients: the role of analytical diversity. Ann Rheum Dis, v. 63 p. 386-94, 2004.

11. HAYDEN, S. R.; BROWN, M. D. Likelihood ratio: a powerful tool for incorporating the results of a diagnostic test into clinical decision making. Ann Emerg Med, v. 33, p. 575-80, 1999.
12. HOCHBERG, M. Updating the American College of Rheumatology revised criteria for the classification of systemic lupus erythematosus. Arthritis Rheum, v. 40, p. 1725-34, 1997.

13. ISENBERG, D. A. et al. The origin, sequence, structure, and consequences of developing anti-DNA antibodies: a human perspective. Arthritis Rheum, v. 37, p.16980, 1994.

14. JUBY, A. et al. Specificity, sensitivity and diagnostic predictive value of selected laboratory generated autoantibody profiles in patients with connective tissue diseases. J Rheumatol, v. 18, p. 354-8, 1991.

15. KAVANAUGH, A. et al. Guidelines for Clinical Use of the Antinuclear Antibody Test and Tests for Specific Autoantibodies to Nuclear Antigens. Arch Pathol Lab Med, v. 124, p. 71-81, 2000.

16. KAVANAUGH, A. F.; SOLOMON, D. H. Guidelines for immunologic laboratory testing in the rheumatic diseases: anti-DNA antibody tests. Arthritis Rheum, v. 47 n. 5 p. 546-55, 2002

17. MANOUSSAKIS, M. et al. Testing for antibodies to ENA and to dsDNA is not indicated in FANA-negative sera. Clin Rheumatol, v. 7 p. 465-9, 1988

18. RUFFATTI, A. et al. Anti-double-stranded DNA antibodies in the healthy elderly: prevalence and characteristics. J Clin Immunol. v. 10, p. 300-3, 1990.

19. RUTTIMANN, E. U. Statistical approaches to development and validation of predictive instruments. Crit Care Clin, v. 10 , p. 19-35, 1994

20. SACKETT, D. L. et al. Evidence-based medicine. How to practice and teach EBM. 2. ed. Edinburgh: Churchill Livingstone; 2000.

21. SOLOMON, D. H. et al. Evidence-based guidelines for the use of immunologic tests: antinuclear antibody testing. Arthritis Rheum, v. 47, n. 4, p. 434-44, 2002.

22. SOX, H. C. The evaluation of a diagnostic test. Ann Rev Med, v. 47, p. 463-71, 1996. 
23. TAN, E. M. et al. Range of antinuclear antibodies in "healthy" individuals. Arthritis Rheum, v. 40, p. 16-11, 1997.

24. TOZZOLI, R. et al. Italian Society of Laboratory Medicine Study Group on the Diagnosis of Autoimmune Diseases. Guidelines for the laboratory use of autoantibody tests in the diagnosis and monitoring of autoimmune rheumatic diseases. Am J Clin Pathol, v. 117, p. 316-24, 2002.

25. VILLALTA, D. et al. Anti-dsDNA antibody avidity determination by a simple reliable ELISA method for SLE diagnosis and monitoring. Lupus, v. 12, p. 31-6, 2003 